\title{
Using Market Information for Banking System Risk Assessment*
}

\author{
Helmut Elsinger, ${ }^{\mathrm{a}}$ Alfred Lehar, ${ }^{\mathrm{b}}$ and Martin Summer ${ }^{\mathrm{c}}$ \\ ${ }^{a}$ Department of Finance, University of Vienna \\ ${ }^{\mathrm{b}}$ Haskayne School of Business, University of Calgary \\ ${ }^{c}$ Economic Studies Division, Oesterreichische Nationalbank
}

We propose a new method for the analysis of systemic stability of a banking system relying mostly on market data. We model both asset correlations and interlinkages from interbank borrowing so that our analysis gauges two major sources of systemic risk: correlated exposures and mutual credit relations that may cause domino effects of insolvencies. We apply our method to a data set of the ten major UK banks and analyze insolvency risk over a one-year horizon. We also suggest a stress-testing procedure by analyzing the conditional asset return distribution that results from the hypothetical failure of individual institutions in this system. Rather than looking at individual bank defaults ceteris paribus, we take the change in the asset return distribution and the resulting change in the risk of all other banks into account. This takes previous stress tests of interlinkages a substantial step further.

JEL Codes: G21, C15, C81, E44.

\footnotetext{
* Martin Summer thanks the Bank of England for its hospitality and support during the work on this project. Helmut Elsinger and Alfred Lehar are grateful for financial support from the Jubiläumsfonds der Oesterreichischen Nationalbank under grant number 10972. We thank Nyeong Lee for valuable research assistance. We thank Charles Goodhart, Mathias Drehmann, Miguel Segoviano, Glenn Hoggarth, Alistair Cunningham, Garry Young, and Simon Wells as well as seminar participants at the Bank of England, the London School of Economics, Imperial College London, the European Central Bank, the University of Frankfurt, and the University of Munich for helpful discussions and comments. The views expressed in this paper are entirely the views of the authors and do not necessarily reflect the views of OeNB. Corresponding author: Summer: Otto-Wagner-Platz 3, A-1011 Wien, Austria; e-mail: martin.summer@oenb.co.at, Tel: +43-1-40420 7212, Fax: +43-1-40420 7299. Other author contact: Elsinger: Brünner Strasse 72, A-1210 Wien, Austria; e-mail: helmut.elsinger@univie.ac.at, Tel: +43-1-4277 38057, Fax: +43-1-4277 38054. Lehar: 2500 University Drive NW, Calgary, AB, Canada T2N 1N4; e-mail: alehar@ucalgary.ca, Tel: +1-(403) 2204567.
} 


\section{Introduction}

We suggest a new method for analyzing systemic financial stability of banking systems relying on market data and nonproprietary accounting data. The central idea is to combine concepts from finance and modern risk management with a network model of interbank loans to analyze the probability of simultaneous failures of banks - often referred to as systemic risk - and to develop a simple stress-testing procedure. We apply our ideas to a data set describing the system of the ten major UK banks and find that this system appears to be very stable. In particular, the likelihood of domino effects of bank insolvencies is very low. We also gain three more general insights. First, we see that for the analysis of systemic risk, defined as the probability assessment of joint default events, the analysis of both correlations and interlinkages is important. An analysis based on single institutions underestimates these events. Second, we see that stress testing of interbank linkages based on idiosyncratic default events only underestimates the impact of bank defaults on the rest of the system by a considerable margin. Third, we see that a simultaneous risk analysis of all major banks in a system can be done even when access to large proprietary microdata sets about individual banks is not available.

\subsection{Related Research}

In a series of recent papers analyzing interbank exposures such as Humphrey (1986), Angelini, Maresca, and Russo (1996), Furfine (2003), Wells (2004), Degryse and Nguyen (2004), VanLelyveld and Liedorp (2004), Upper and Worms (2004), and Mistrulli (2005), it has become common practice to investigate contagious defaults that result from the hypothetical failure of some single institution. This sort of analysis is able to capture the effect of idiosyncratic bank failures (e.g., because of fraud). It emphasizes one source of systemic risk, namely interbank linkages, and ignores the other, i.e., it is silent on correlation between banks' exposures. We believe that a meaningful risk assessment is only possible by studying both aspects in conjunction. Our paper builds on the model developed in Elsinger, Lehar, and Summer (2004), which incorporates both sources of systemic risk simultaneously. While in their model the distribution of 
bank asset returns is inferred from bank-specific data on market and credit risk exposures derived from a combination of various proprietary data sets of the Austrian Central Bank (OeNB), in contrast, in this paper the distribution of bank asset returns is inferred indirectly from stock market return data. The method of indirectly inferring bank asset return correlations from market data builds on the work of Lehar (2005).

\subsection{An Overview of the Model and Main Results}

We reconstruct a time series for the market values of assets for ten large publicly traded UK banks by viewing equity as a call option on total assets. We analyze the covariance structure of asset returns and simulate potential risk situations for the banking system as a whole based on this analysis. The advantage of this approach to model the uncertainty of bank asset returns lies in the fact that it does not depend on proprietary data sources. Of course, this advantage does not come without a price. While in highly developed financial systems stock market data are likely to incorporate all relevant public information on a bank's risk exposure, the data do not necessarily incorporate private information that is often contained in supervisory bank microdata and loan registers. Private information is, however, likely to be important for assessing the risks of a bank due to the opaque nature of bank asset values. One way to see the approach to bank asset risk modeling suggested in this paper is that it offers an alternative approach when private information - as is very often the case in practice - is not available.

Using a network model of the interbank market (following the model of Elsinger, Lehar, and Summer 2004) we investigate default probabilities and so-called domino effects. More significantly, we analyze the differences that arise in risk assessment when we take a naive approach, neglecting correlations; when we analyze correlations but ignore interlinkages; and finally, when we additionally take interlinkages into account. We then model the impact of various stress scenarios for the banking system by using a method that preserves the idea of previous papers examining scenarios where each bank in the system fails one at a time. But in contrast to this literature, we do so in a way that is consistent with the correlation structure of asset returns. Put another way, rather than simply removing a bank 
from the system one at a time (leaving everything else equal) we look at the conditional distribution of asset returns resulting from the event that one bank fails.

The empirical analysis gives the following main insights. First, the UK banking system appears to be very stable. In particular, the likelihood of domino effects is very low. Second, the simultaneous consideration of correlation and interlinkages does indeed make a difference for the assessment of systemic financial stability. In particular, the probability of systemic events such as the joint breakdown of major institutions is underestimated when correlations between banks are ignored. We can also show that ignoring interlinkages leads to an underestimation of joint default events. Third, the analysis uncovers substantial differences between banks concerning their impact on others in stress scenarios and clearly identifies institutions with a high systemic impact.

Finally, we demonstrate the importance of the assumption about the source of the shock when studying the consequences of a bank default. While the previous literature has studied idiosyncratic shocks, only our model captures systematic shocks too. We suggest a hypothetical decomposition into idiosyncratic and systematic sources of a shock that may hit a bank. In this way we can investigate not only the extreme cases studied in the existing literature but also intermediate cases. By measuring the expected shortfall for all other banks in the system conditional on the default of one bank, we demonstrate that a systematic shock has a much higher impact on financial stability than an idiosyncratic one. Basing a stress test entirely on idiosyncratic shock scenarios may therefore considerably underestimate the impact of the shock on the banking system as a whole. The impact of a bank's default on the banking system is much smaller if we assume an idiosyncratic shock than if we assume that the bank defaults following a macroeconomic shock.

\section{A System Perspective on Risk Exposure for Banks}

Our network model of interbank credits is a version of the model of Eisenberg and Noe (2001). We refer the reader to this paper for technical details. For our purpose of risk analysis, we extend their model to include uncertainty. Consider a set $\mathcal{N}=\{1, \ldots, N\}$ of banks. Each bank $i \in \mathcal{N}$ is characterized by a given value $e_{i}$ net of interbank 
positions and its nominal liabilities $l_{i j}$ against other banks $j \in \mathcal{N}$ in the system. The entire banking system is thus described by an $N \times N$ matrix $L$ and a vector $e \in \mathbb{R}^{N}$. We denote this system by the pair $(L, e)$.

The total value of a bank is the value of $e_{i}$ plus the value of all payments received from counterparties in the interbank market minus the interbank liabilities. If for a given pair $(L, e)$ the total value of a bank becomes negative, the bank is insolvent. In this case we assume that creditor banks are rationed proportionally. Denote by $d \in \mathbb{R}_{+}^{N}$ the vector of total obligations of banks toward the rest of the system, i.e., $d_{i}=\sum_{j \in \mathcal{N}} l_{i j}$. Define a new matrix $\Pi \in[0,1]^{N \times N}$ which is derived from $L$ by normalizing the entries by total obligations.

$$
\pi_{i j}=\left\{\begin{array}{cc}
\frac{l_{i j}}{d_{i}} & \text { if } d_{i}>0 \\
0 & \text { otherwise }
\end{array}\right.
$$

We describe a banking system as a tuple $(\Pi, e, d)$ for which we define a clearing payment vector $p^{*}$. The clearing payment vector has to respect limited liability of banks and proportional sharing in case of default. It denotes the total payments made by the banks under the clearing mechanism. It is defined by

$$
p_{i}^{*}=\left\{\begin{array}{cl}
d_{i} & \text { if } \sum_{j=1}^{N} \pi_{j i} p_{j}^{*}+e_{i} \geq d_{i} \\
\sum_{j=1}^{N} \pi_{j i} p_{j}^{*}+e_{i} & \text { if } d_{i}>\sum_{j=1}^{N} \pi_{j i} p_{j}^{*}+e_{i} \geq 0 \\
0 & \text { if } \sum_{j=1}^{N} \pi_{j i} p_{j}^{*}+e_{i} \quad<0
\end{array}\right.
$$

This can be written more compactly as

$$
p^{*}=\min \left[d, \max \left(\Pi^{\prime} p^{*}+e, 0\right)\right],
$$

where the min and max operators denote the componentwise maximum and minimum. The clearing payment vector directly gives us two important insights: for a given structure of liabilities and bank values $(\Pi, e, d)$ we can identify insolvent banks $\left(p_{i}^{*}<d_{i}\right)$ and derive the recovery rate for each defaulting bank $\left(\frac{p_{i}^{*}}{d_{i}}\right)$. 
To find a clearing payment vector, we employ a variant of the fictitious default algorithm developed by Eisenberg and Noe (2001). They prove that under mild regularity conditions, a unique clearing payment vector for $(\Pi, e, d)$ always exists. These results extend to our framework as well.

From the solution of the clearing problem, we can gain additional economically important information with respect to systemic stability. Default of bank $i$ is called fundamental if bank $i$ is not able to honor its promises under the assumptions that all other banks honor their promises

$$
\sum_{j=1}^{N} \pi_{j i} d_{j}+e_{i}-d_{i}<0 .
$$

A contagious default occurs when bank $i$ defaults only because other banks are not able to keep their promises, i.e.,

$$
\begin{array}{lll}
\sum_{j=1}^{N} \pi_{j i} d_{j}+e_{i}-d_{i} \geq & 0 \\
& \text { but } \\
\sum_{j=1}^{N} \pi_{j i} p_{j}^{*}+e_{i}-d_{i}< & 0 .
\end{array}
$$

To use the model for risk analysis, we extend it to an uncertainty framework by assuming that $e$ is a random variable. As there is no closed-form solution for the distribution of $p^{*}$, given the distribution of $e$, we have to resort to a simulation approach where each draw is called a scenario. By the theorem of Eisenberg and Noe (2001) we know that there exists a (unique) clearing payment vector $p^{*}$ for each scenario. Thus from an ex ante perspective we can assess expected default frequencies from interbank credits across scenarios as well as the expected severity of losses from these defaults given that we have an idea about the distribution of $e$. Furthermore, we are able to decompose insolvencies across scenarios into fundamental and contagious defaults.

To pin down the distribution of $e$ we choose the following approach: assume that there are two dates: $t=0$, which is the observation date, and $t=T$, which is a hypothetical clearing date where 
all interbank claims are settled according to the clearing mechanism. At $t=0$ the interbank exposures are observed. Assuming that these positions remain constant for the time horizon under consideration, they constitute the matrix $L$ at $T$. This implies that the liability structure of the banks remains constant. Yet, there is empirical evidence (see Shibut 2002) that the creditors of distressed banks withdraw unsecured funds before the bank fails. ${ }^{1}$ If creditors learn between $t=0$ and $t=T$ that a bank is distressed, they will try to withdraw their unsecured funds. ${ }^{2}$ If this were interbank funds, this would change the assumed seniority structure. Though this could reduce the risk of contagion and increase the loss to a deposit insurer, it will not change the risk of fundamental default.

Given the assumption of constant interbank claims, the value of the banks at $t=T$ depends solely on the realization of the random value of $e$ at $T$, which is defined as the net assets before interbank positions are taken into account, i.e.,

$$
e_{i}=V_{i}(T)-D_{i}(T)-\left(\sum_{j=1}^{N} \pi_{j i} d_{j}-d_{i}\right),
$$

where $V_{i}(T)$ is the value of total assets of bank $i$ and $D_{i}(T)$ is the value of total liabilities of bank $i$ at time $T$. As in Duan (1994) we assume that the liabilities are insured and hence accrue at the riskfree interest rate. Therefore, $D_{i}(T)=D_{i}(0) e^{r T}$ and the distribution of $e_{i}$ is determined by the distribution of $V_{i}(T)$ only.

Given the lack of available data on UK banks' net asset positions, we model $V_{i}(t)$ as a geometric Brownian motion under the objective probability measure $P$, i.e.,

$$
d V_{i}=\mu_{i} V_{i} d t+V_{i} \sigma_{i} d B_{i}
$$

where $B_{i}$ is a one-dimensional Brownian motion. ${ }^{3}$ An important innovation in our research is that we explicitly allow the asset values

\footnotetext{
${ }^{1}$ On the other hand, Cocco, Gomes, and Martins (2004) show that for overnight loans, lending relationships do play a role in the interbank market and that during the Russian financial crisis, banks relied on relationship lending even more than usual.

${ }^{2}$ In case of netting agreements, another way to reduce exposures could be to take up funds from the troubled institution.

${ }^{3}$ This approach follows Merton (1974) and has been applied to banking systems as a whole by Lehar (2005).
} 
of different banks to be correlated, i.e., the instantaneous correlation of $B_{i}(t)$ and $B_{j}(t)$ denoted by $\rho_{i j}$ might be different from zero for all $i$ and $j$. Given the drift parameters $\mu_{i}$ and the variance-covariance matrix $\Sigma$ where $\sigma_{i j}=\sigma_{i} \sigma_{j} \rho_{i j}$, we are able to simulate the future asset values $V_{i}^{s}(T)$ of all banks simultaneously taking the correlation structure between their asset values into account. For details we refer the reader to Elsinger, Lehar, and Summer (2005).

By correcting $V_{i}^{s}(T)$ for interbank positions and deducting total liabilities $D_{i}(T)$ in each scenario, we construct the net income position for each bank as follows:

$$
e_{i}^{s}=V_{i}^{s}(T)-D_{i}(T)-\left(\sum_{j=1}^{N} \pi_{j i} d_{j}-d_{i}\right) .
$$

This together with the interbank matrix $L$ determines a clearing payment vector for each realization. Based on this information, we conduct our risk analysis.

Neither the initial bank asset value $V(0)$ nor the drift $\mu$ nor the variance covariance matrix $\Sigma$ are observable. Our approach therefore requires not only an estimate of interbank liabilities, but also estimates of the parameters of the stochastic processes governing bank assets, and of the market values of total assets. The simulation is then performed using the estimated values. An overview of the model is given in figure 1. Like all market or credit risk models, we have to assume a time horizon, which we set to one year.

\section{Estimating Bank Asset Risk from Market Data}

A bank's asset portfolio consisting of loans to nonbanks, interbank loans, traded securities, and many other items is funded by debt and equity. So in order to estimate the value of total assets, we need information on the future development of asset values and the face value of debt. The problem is that the actual market value of assets is not directly observable. ${ }^{4}$ What is, however, observable is the market value of equity and the face value of debt for each publicly traded

\footnotetext{
${ }^{4}$ The dynamics of the market value of a bank's liabilities are not important, as the bank is assumed to default whenever the market value of the assets is below the promised payments, which is the book value of liabilities.
} 
Figure 1. The Structure of the Model

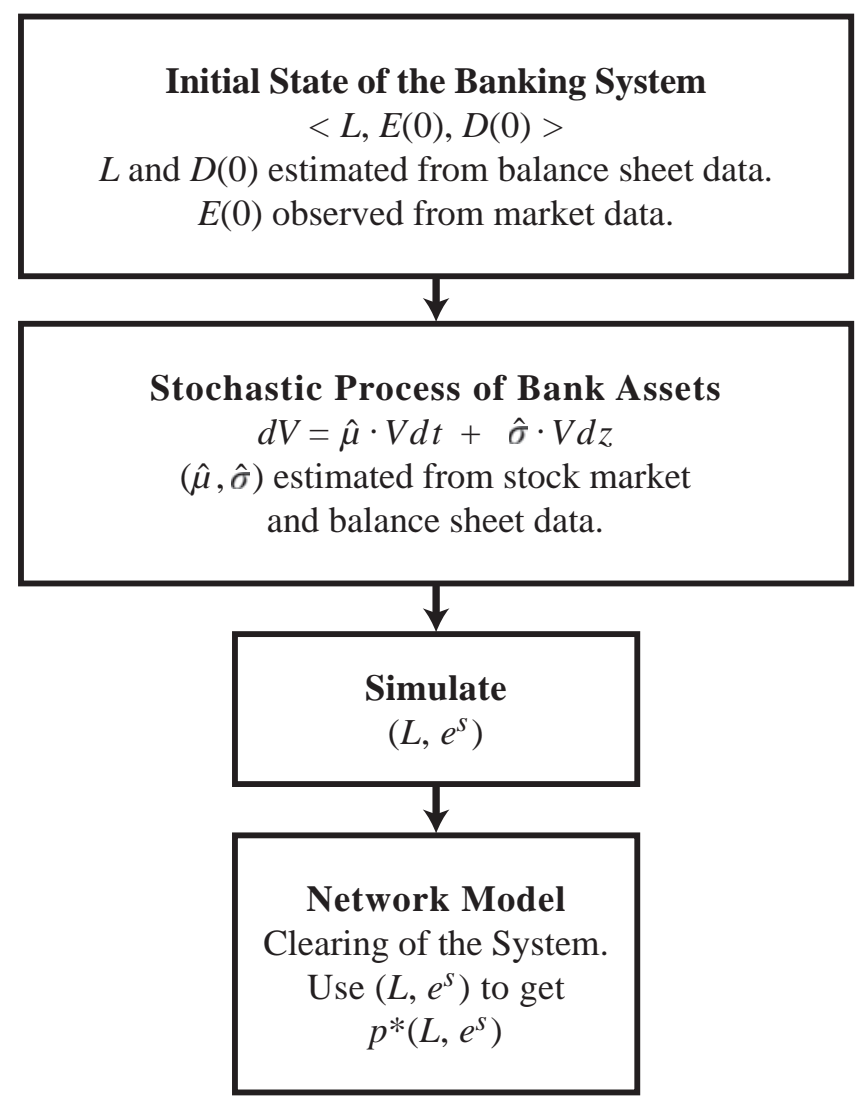

bank. By viewing equity as a European call option on the bank's assets with a strike price equal to the value of debt at maturity, we can make use of this information to get an estimate of the market value of assets for each publicly traded bank. ${ }^{5}$

Denote the equity of bank $i$ at $t$ by $E_{i}(t)$ and the total face value of its interest-bearing debt by $D_{i}(t)$, which is assumed to have a time to maturity of $T_{1}$. We assume that all bank debt is insured and will

\footnotetext{
${ }^{5}$ This idea goes back to Black and Scholes (1973) and Merton (1973).
} 
therefore grow at the risk-free rate. ${ }^{6}$ The value of bank equity is then given by the call option price formula:

$$
E_{i}(t)=V_{i}(t) \Phi\left(k_{i}(t)\right)-D_{i}(t) \Phi\left(k_{i}(t)-\sigma_{i} \sqrt{T_{1}}\right),
$$

where

$$
k_{i}(t)=\frac{\ln \left(V_{i}(t) / D_{i}(t)\right)+\left(\sigma_{i}^{2} / 2\right) T_{1}}{\sigma_{i} \sqrt{T_{1}}}
$$

and $\Phi(\cdot)$ is the cumulative standard normal distribution. ${ }^{7}$ This formula is invertible in the sense that given $\left(E_{i}(t), D_{i}(t), \sigma_{i}, T_{1}\right)$ are all larger than 0 , the value of total assets $V_{i}(t)$ is uniquely determined. Hence, given an estimate of $\sigma_{i}$, we can infer the market value of total assets from observable data.

The parameters of the stochastic processes are estimated using a maximum likelihood approach as developed in Duan (1994) and Duan (2000). As we are interested in the joint behavior of the total assets, we extend this technique by estimating the parameters of all banks simultaneously.

Given sequences $\boldsymbol{E}_{i}=\left(E_{i}(t)\right)$ and $\boldsymbol{D}_{i}=\left(D_{i}(t)\right), t \in\{1 \ldots m\}$ and $i \in\{1 \ldots N\}$ of observed historical equity and debt values, respectively, the parameters $(\mu, \Sigma)$ of the asset value processes can be estimated by maximizing the following log-likelihood function: ${ }^{8}$

$$
\begin{aligned}
L(E) & =-\frac{(m-1) N}{2} \ln (2 \pi)-\frac{m-1}{2} \ln |\Sigma| \\
& -\sum_{t=2}^{m}\left\{\frac{N}{2} \ln \left(h_{t}\right)+\frac{1}{2 h_{t}}\left(\hat{x}_{t}-h_{t} \alpha\right)^{\prime} \Sigma^{-1}\left(\hat{x}_{t}-h_{t} \alpha\right)\right\} \\
& -\sum_{t=2}^{m} \sum_{i=1}^{N}\left[\ln \hat{V}_{i, t}\left(\sigma_{i}\right)+\ln \Phi\left(\hat{k}_{i, t}\right)\right],
\end{aligned}
$$

where $\alpha_{i}=\mu_{i}-\frac{1}{2} \sigma_{i}^{2} ; h_{t}$ denotes the time increment from $t-1$ to $t ; \hat{V}_{i, t}\left(\sigma_{i}\right)$ is the solution of equation (4) given $\sigma_{i} ; \hat{k}_{i, t}$ corresponds to $k_{i}(t)$ in equation (5) with $V_{i}(t)$ replaced by $\hat{V}_{i, t}\left(\sigma_{i}\right)$; and $\hat{x}_{i t}=$ $\ln \left(\hat{V}_{i, t}\left(\sigma_{i}\right) / \hat{V}_{i, t-1}\left(\sigma_{i}\right)\right)$.

\footnotetext{
${ }^{6}$ Relaxing this assumption will not dramatically change the results, since the paper's focus is not on deposit insurance pricing. From the available data, we cannot determine the amount of uninsured debt for every bank.

${ }^{7}$ Note, as the strike price equals $D_{i}(t) e^{r T_{1}}, r$ cancels out in the Black-Scholes formula.

${ }^{8}$ For the derivation of the likelihood function see Elsinger, Lehar, and Summer (2005).
} 
For the estimation of the parameters $\mu$ and $\Sigma$, we assume that the time to maturity of debt, $T_{1}$, equals one year. We use one year of weekly market values of total equity $E_{i}(t)$. From the estimation we get a set of parameters for every bank in the sample, which can then be used to back out the estimated asset values $\hat{V}_{i}(t)$ for every given equity price for each week during the past year. Put another way, we are able to estimate the value of total assets at each observation date for each bank.

In line with the standard risk management literature, we assume throughout the paper that the returns on the banks' asset portfolios are normally distributed. One could consider alternative distributions to include frequently observed characteristics of equity return series like fat tails. ${ }^{9}$ However, this would be inconsistent with the assumptions of the estimation procedure in equation (4).

\section{The Data}

To apply the framework described in section 2 to the data, we need to determine the interbank exposures (the matrix $L$ ) as well as noninterbank exposures (the net worth positions $e_{i}$ ) for each bank. Since we describe the risks to $e_{i}$ by the stochastic process approach, we can only consider banks that are publicly traded. All banks that are not in this category are summarized in a residual position. To estimate the parameters of the stochastic process governing the value of banks' assets, we use weekly stock market data for 2003 from Bloomberg. Total liabilities are taken from the Bank of England's bank balance sheet data.

Central banks usually have quite detailed information about their domestic banks' on-balance-sheet interbank positions. This information is available in form of balance sheet reports and supervisory data. The information is partial in several dimensions. First, the balance sheet does not contain exposures at a bilateral level. Some bilateral exposures can, however, be recovered by combining balance sheet information with other data sources. ${ }^{10}$ Second, the balance

\footnotetext{
${ }^{9}$ Note that normality is assumed for the asset returns. The equity returns, where most studies document skewness and kurtosis, are not normally distributed in this setting.

${ }^{10}$ For instance, in their study for Austria, Elsinger, Lehar, and Summer (2004) can reconstruct 72 percent of on-balance-sheet interbank exposures exactly. Wells
} 
sheet data allow a reconstruction of the interbank network only for the domestic banks, as data on overseas banks are usually only available as an aggregate position. The procedure thus can usually cover only banks that are owned domestically or branches and subsidiaries of foreign banks located within the country. Finally, off-balance-sheet information and exposures arising from intraday payment and settlement are not included.

For the estimation of an interbank exposure matrix, we look at the ten largest UK resident banks, an aggregate position for all other UK resident banks, and an aggregate position for foreign banks (i.e., branches and subsidiaries of overseas banks located within the United Kingdom). ${ }^{11}$ This gives us a 10 by 10 matrix of interbank exposures of money market loans and deposits. As mentioned in Wells (2004), these data are unconsolidated. This is a measurement problem because the UK banking system is highly concentrated and the largest banking groups often have significant overseas subsidiaries and/or other subsidiaries located within the United Kingdom. But although potentially important exposures are excluded, we believe our data set provides an adequate estimate of the interbank liabilities. Wells (2004) finds that the data cover around 75 percent of total (on-balance-sheet) unsecured interbank assets. ${ }^{12}$ He furthermore finds that OTC derivative exposures are small relative to on-balancesheet interbank exposures. In table 1, we give an account of the size of on-balance-sheet interbank business for the last quarter of 2003 .

Partial information about the interbank liability matrix $L$ is available from balance sheet data. The bank-by-bank record of total interbank assets and liabilities provides the column and row sums of the matrix $L$. Further, some structural information is available. For example, the diagonal of $L$ must contain only zeros since banks do

(2004) combines balance sheet data with the large exposure statistics to get an improved estimate on bilateral positions compared to an estimate that relies on balance sheet information only.

${ }^{11}$ As we have no information on default probabilities of foreign banks and the other UK banks, we assume in the following analysis that the exposure to these banks is well diversified and thus has zero default probability. To analyze the impact of interbank exposure to these banks, one could come up with ad hoc scenarios, like assuming that a certain fraction of foreign interbank debt is lost. Our framework allows us to analyze the impact of such scenarios on contagion.

${ }^{12}$ The other 25 percent is accounted for by commercial paper and certificates of deposit. 
Table 1. UK-System Interbank Loans and Deposits in 2003:Q4

\begin{tabular}{|c|c|c|c|c|}
\hline \multirow[b]{2}{*}{ Bank Group } & \multicolumn{2}{|c|}{ Interbank Assets } & \multicolumn{2}{|c|}{ Interbank Liabilities } \\
\hline & $\begin{array}{c}\text { Billion } \\
\text { GBP }\end{array}$ & $\begin{array}{c}\% \text { of } \\
\text { Total }\end{array}$ & $\begin{array}{c}\text { Billion } \\
\text { GBP }\end{array}$ & $\begin{array}{l}\% \text { of } \\
\text { Total }\end{array}$ \\
\hline Major UK Banks & 269.97 & $67.78 \%$ & 270.07 & $67.81 \%$ \\
\hline Other UK Banks & 3.81 & $0.96 \%$ & 2.89 & $0.72 \%$ \\
\hline Foreign Banks & 124.51 & $31.26 \%$ & 125.39 & $31.47 \%$ \\
\hline Total & 398.29 & $100 \%$ & 398.29 & $100 \%$ \\
\hline
\end{tabular}

not have claims and liabilities against themselves. For the UK banking system, limited information about certain large bilateral exposures is also available (see Wells 2004). But these data are based on a different definition of interbank exposure; for example, they include some off-balance-sheet exposures and so are not directly comparable with the loan and deposit data that we use to estimate the matrix $L$. Given our aim of using only market data, we do not incorporate these data into our analysis.

As fundamental defaults are determined by the sum of all claims and liabilities in the interbank market, the sum of individual rows and columns is sufficient for this purpose. But to calculate a clearing payment vector and to identify contagious defaults, the bilateral exposures have to be estimated based on this partial information. The fact that we cannot observe individual bilateral exposures should be reflected in the fact that these entries in the matrix are treated homogeneously in the estimation process. We formulate the estimation of the unobservable parts of the $L$ matrix as an entropy optimization problem.

Intuitively, this procedure finds a matrix that treats all entries as balanced as possible and satisfies all known constraints. This can be formulated as minimizing a suitable measure of distance between 
the estimated matrix and a matrix that reflects our a priori knowledge. The so-called cross-entropy measure is a suitable concept for this task (see Fang, Rajasekera, and Tsao [1997] or Blien and Graef [1997]). A detailed description of the estimation procedure and the estimated matrix can be found in Elsinger, Lehar, and Summer (2004).

Our assumption on the structure of $L$ will not affect fundamental defaults but will certainly have an impact on the number of contagious defaults. On the one hand, spreading out interbank loans among many banks might make the banking system more resilient toward shocks (Allen and Gale 2000); on the other hand, it might allow contagion to spread out more (consistent with the empirical findings of Elsinger, Lehar, and Summer 2004). To check for robustness we also estimated $L$ matrices that are as sparse as possible. ${ }^{13}$ Table 7 (shown at the end of section 7 ) contains some results of this robustness check.

\section{Risk Analysis: Status Quo}

For the estimate of the interbank matrix and the observed values of total equity and liabilities at the end of December 2003, our framework provides statistics of default scenarios in one year's time, i.e., at the end of 2004. Note that our model allows for a decomposition of default events into "fundamental" and "contagious" defaults. The results of the simulation are reported in table 2 .

We see that the UK banking system-at least as far as the ten largest institutions are concerned-appears to be extremely stable. There are scenarios with nine defaults in total; however, their probability is practically zero, since it occurs in only one scenario out of 100,000 . The probability that one or more defaults occur in the entire system over a one-year horizon given the December 2003 starting position is 4.7 percent. The probability of observing a domino effect is practically zero.

Various parameters in the clearing process can be changed to check the sensitivity of the results on the banking system's aggregate default statistics. When we change the procedure by netting

\footnotetext{
${ }^{13}$ We had to rely on heuristics for this estimation, since we are not aware of a well-suited algorithm for our problem.
} 
Table 2. Frequency of Fundamentally and Contagiously Defaulting Banks Grouped by the Number of Fundamental Defaults (First Column)

\begin{tabular}{|c|r|r|r|r|r|r|r|r|r|}
\hline \multirow{2}{*}{$\begin{array}{c}\text { Fundamental } \\
\text { Defaults }\end{array}$} & \multicolumn{7}{|c|}{ Contagious Defaults } \\
\cline { 2 - 9 } & \multicolumn{1}{|c|}{$\mathbf{0}$} & $\mathbf{1}$ & $\mathbf{2}$ & $\mathbf{0}$ & $\mathbf{1}$ & $\mathbf{2}$ & $\mathbf{3}$ & $\mathbf{4}$ & $\mathbf{5}$ \\
\hline 0 & 95335 & 0 & 0 & 95335 & 0 & 0 & 0 & 0 & 0 \\
1 & 3985 & 34 & 2 & 3971 & 49 & 1 & 0 & 0 & 0 \\
2 & 409 & 37 & 8 & 402 & 45 & 5 & 1 & 0 & 1 \\
3 & 98 & 23 & 2 & 93 & 25 & 5 & 0 & 0 & 0 \\
4 & 31 & 11 & 4 & 27 & 14 & 3 & 2 & 0 & 0 \\
5 & 11 & 4 & 2 & 6 & 6 & 5 & 0 & 0 & 0 \\
6 & 2 & 1 & 0 & 0 & 2 & 1 & 0 & 0 & 0 \\
7 & 0 & 0 & 0 & 0 & 0 & 0 & 0 & 0 & 0 \\
8 & 0 & 1 & 0 & 0 & 1 & 0 & 0 & 0 & 0 \\
\hline Total & 99871 & 111 & 18 & 99834 & 142 & 20 & 3 & 0 & 1 \\
\hline Note: The total number of scenarios is $100,000$. \\
\hline
\end{tabular}

all bilateral exposures before the clearing mechanism is applied, the mean default probability as well as its standard deviation increase slightly compared to the case without netting. This is due to increasing second round effects or contagious defaults (see table 2). ${ }^{14}$ If in addition we assume that insolvent institutions do not repay their interbank creditors after netting of bilateral exposures - which might be interpreted according to Elsinger, Lehar, and Summer (2004) as a "short-term" scenario - the probability of contagious defaults hardly rises at all and the default statistics remain virtually unchanged.

\footnotetext{
${ }^{14}$ Netting bilateral exposures might increase or decrease contagion (see Elsinger, Lehar, and Summer [2005] for examples). In our data set most of the banks are harmed by bilateral netting.
} 
Table 3. Distribution of Individual Default Probabilities and Distance to Default

\begin{tabular}{|c|c|c|c|c|c|c|c|c|c|c|}
\hline Bank & $\mathbf{1}$ & $\mathbf{2}$ & $\mathbf{3}$ & $\mathbf{4}$ & $\mathbf{5}$ & $\mathbf{6}$ & $\mathbf{7}$ & $\mathbf{8}$ & $\mathbf{9}$ & \multicolumn{1}{c|}{$\mathbf{1 0}$} \\
\hline Default Prob & $0 \%$ & $0.01 \%$ & $0.02 \%$ & $0.02 \%$ & $0.04 \%$ & $0.10 \%$ & $0.23 \%$ & $0.59 \%$ & $0.68 \%$ & $4.06 \%$ \\
DD & 7.11 & 4.78 & 3.48 & 3.46 & 3.31 & 3.10 & 2.90 & 2.42 & 2.45 & 1.73 \\
\hline
\end{tabular}

Looking at the distribution of the individual Merton-default probabilities of the ten banks in our system, we see that the system is very stable. We have one outlier with a one-year default probability of 4 percent; all other individual default probabilities are in the range between 0 percent and 0.68 percent. The distribution of individual default probabilities is shown in table 3 . The table also shows the distance to default under the objective probability, which is measured as

$$
d d_{i}(T)=\frac{\left(\hat{\mu}_{i}-\frac{1}{2} \hat{\sigma}_{i}^{2}\right) T+\ln \frac{V_{i}(0)}{D_{i}(T)}}{\hat{\sigma}_{i} \sqrt{T}} .
$$

The results should be interpreted with caution. The focus of our model is not to derive individual default probabilities but rather to investigate the impact of correlation between bank portfolios versus contagion as well as to derive a stress-testing framework to identify system-relevant banks. The default probabilities of the Merton model should mainly be seen as providing a ranking of default risk among banks. ${ }^{15}$

\section{The Role of Correlation and Interlinkages}

Banking regulation has traditionally been more focused on individual banks than on the system as a whole. Hence, regulators are typically interested in the marginal distribution of $V_{i}(t)$ and less attention is given to the joint distribution of $V(t)$. Whereas this marginal approach gives the correct default probabilities of individual banks, the estimates for joint defaults based on the marginal distributions are, in general, not correct. The question is whether the improvement in estimating the probability of joint defaults by taking the correlation

\footnotetext{
${ }^{15}$ To get a precise default probability estimate, one could follow KMV and use a mapping of Merton default probabilities into empirical PDs.
} 
Table 4. Number of Simultaneously Defaulting Banks across Simulations

\begin{tabular}{|c|c|c|c|c|}
\hline \multirow{2}{*}{$\begin{array}{l}\text { Simultaneous } \\
\text { Defaults }\end{array}$} & \multirow{2}{*}{$\begin{array}{c}\text { Marginal } \\
\text { Distribution }\end{array}$} & \multirow{2}{*}{$\begin{array}{c}\text { Joint } \\
\text { Distribution }\end{array}$} & \multicolumn{2}{|c|}{ Interbank Market } \\
\hline & & & No Netting & Full Netting \\
\hline 0 & 94523 & 95335 & 95335 & 95335 \\
\hline 1 & 5421 & 4021 & 3985 & 3971 \\
\hline 2 & 56 & 454 & 443 & 451 \\
\hline 3 & 0 & 123 & 137 & 139 \\
\hline 4 & 0 & 46 & 62 & 57 \\
\hline 5 & 0 & 17 & 24 & 26 \\
\hline 6 & 0 & 3 & 10 & 9 \\
\hline 7 & 0 & 0 & 3 & 10 \\
\hline 8 & 0 & 1 & 0 & 1 \\
\hline 9 & 0 & 0 & 1 & 1 \\
\hline 10 & 0 & 0 & 0 & 0 \\
\hline
\end{tabular}

structure into account makes this more elaborate technique really necessary. To examine this, we compare the (simulated) number of joint defaults for three different procedures

1. based on the marginal distributions only, i.e., assuming that the covariances are zero, ${ }^{16}$

2. based on the joint distribution, and

3. based on the joint distribution taking the financial linkages between banks into account.

The results, shown in table 4 , demonstrate that taking the correlation structure into account can have a considerable impact on estimates of default. The number of scenarios with a single defaulting bank decreases. In contrast, both the number of scenarios with no default at all and the number of scenarios where two or more

\footnotetext{
${ }^{16}$ For a description of the simulation procedure, see appendix 1.
} 
banks default simultaneously increase. This result is further amplified when bank interlinkages (i.e., the potential for contagion) are taken into account.

This analysis shows that, from the viewpoint of systemic stability, both correlated exposures and interlinkages do matter. Ignoring the systemwide perspective -i.e., ignoring correlations and interlinkages - leads to a considerable underestimation of the probability of a systemic crisis. If we do not take into account interlinkages, the amount of underestimation of joint default probabilities is, from a practical point of view, perhaps not too big. Ignoring correlations, however, leads to an underestimation of joint default events by a significant margin. ${ }^{17}$

\section{Risk Analysis: Stress Testing}

Stress testing provides another measure of systemic stability, but importantly it also allows financial regulators to identify individual banks that may pose systemic risks. With the exception of Elsinger, Lehar, and Summer (2004), the literature on interbank linkages and domino effects has focused on stress tests that assume the default of single institutions, leaving the financial condition of the other banks unaffected. The implicit assumption of this previous research is that the cause of bank failure is an idiosyncratic shock that hits just one bank at a time. This approach is useful to study the consequences of fraud or to study the contagion impact within a banking system where banks' asset portfolios are rather uncorrelated, e.g., geographical diversification. But to look at stress testing from a more general perspective, we have to be more specific on the source of the assumed default.

From the perspective of systemic stability, the assumption of idiosyncratic shocks might lead to an underestimation of systemic risk, as there is evidence that the correlation between bank portfolios is generally positive. ${ }^{18}$ When conducting stress testing on a system

\footnotetext{
${ }^{17}$ The results are quite robust with respect to the estimation procedure of the interbank matrix $L$. Using different estimates for $L$, we got similar results in terms of contagion (see table 7).

${ }^{18}$ See, for example, Nicolo and Kwast (2002) or Lehar (2005). While the new internal ratings-based approach of Basel II considers correlations of bank loans within a bank portfolio, our focus is on the correlation between bank portfolios.
} 
level, the impact of a macroeconomic shock that hits the whole banking system should be a major concern for institutions charged with maintaining financial stability. Such a shock affects all banks to a certain degree, depending on their asset composition. Thus, we extend the current stress-testing framework by modeling a second reason for a bank's default - a systematic shock. If there is a positive correlation in banks' asset values, it is likely that if one bank defaults because of a declining asset value, other banks may also be expecting difficulties.

We model systematic shocks by deriving the multivariate conditional distribution for the banks' asset values. The idea is as follows: suppose that the regulator knows the joint unconditional distribution of the banks' asset values and observes that one bank has defaulted, partly due to a systematic shock. It is now rational for the regulator to update his or her beliefs on the joint distribution and compute the conditional distribution of all the other banks' asset values, given that one bank's asset value is below the bankruptcy threshold. Under this conditional distribution, default probabilities, the probability of contagion, and the losses to the deposit insurer would be expected to increase if bank asset values are positively correlated. Conducting such an analysis ex ante will allow the regulator to rank banks according to the impact of their default on the banking system and thus identify system-relevant banks. Appendix 2 outlines the simulation technique in detail.

Table 5 shows each bank's probability of default conditional on the default of bank $i$. We find a large variation across banks. For instance, the first bank has only a very small impact on the fundamental default probability of all the other banks, but is itself affected most by the hypothetical defaults of all the others. Banks 1, 4, and 7 have, on average, a much weaker impact on the others than banks 2 , $3,5,6,8,9$, and 10 . On the other hand, banks $1,3,4,5$, and 7 are, on average, most affected by the change in asset correlations brought about by the default of other banks in the system. The pattern that seems to appear in this table is that the larger the distance to default, the higher the impact of a default on the other banks. The reason is that a bank with a large distance to default needs a large negative shock to make the bank default. In conjunction with the positive asset correlations, all other banks are seriously hit by this (systematic) shock, too. Yet, a closer look at table 5 reveals that, 
Table 5. Probabilities of Default Conditional on the Failure of One Bank

\begin{tabular}{|c|r|r|r|r|r|r|r|r|r|c|}
\hline \multicolumn{10}{|c|}{ Banks } & DD \\
\hline No 1 & No 2 & No 3 & No 4 & No 5 & No 6 & No 7 & No 8 & No 9 & No 10 & \\
\hline- & $92.7 \%$ & $62.6 \%$ & $49.0 \%$ & $62.9 \%$ & $98.8 \%$ & $55.5 \%$ & $64.3 \%$ & $77.0 \%$ & $97.7 \%$ & 1.73 \\
$0.5 \%$ & - & $5.4 \%$ & $2.0 \%$ & $6.5 \%$ & $56.8 \%$ & $2.1 \%$ & $14.2 \%$ & $12.0 \%$ & $60.1 \%$ & 3.46 \\
$1.2 \%$ & $16.1 \%$ & - & $5.7 \%$ & $10.6 \%$ & $79.4 \%$ & $6.3 \%$ & $19.3 \%$ & $31.4 \%$ & $88.4 \%$ & 3.10 \\
$7.9 \%$ & $55.6 \%$ & $46.9 \%$ & - & $42.4 \%$ & $74.4 \%$ & $26.9 \%$ & $51.4 \%$ & $44.5 \%$ & $97.1 \%$ & 2.45 \\
$3.8 \%$ & $54.8 \%$ & $34.0 \%$ & $14.3 \%$ & - & $55.0 \%$ & $14.7 \%$ & $38.6 \%$ & $68.7 \%$ & $77.6 \%$ & 2.90 \\
$0.0 \%$ & $0.0 \%$ & $0.0 \%$ & $0.0 \%$ & $0.0 \%$ & - & $0.0 \%$ & $0.0 \%$ & $0.0 \%$ & $0.0 \%$ & 7.11 \\
$8.3 \%$ & $52.7 \%$ & $47.6 \%$ & $24.3 \%$ & $32.7 \%$ & $68.5 \%$ & - & $48.5 \%$ & $70.2 \%$ & $81.6 \%$ & 2.42 \\
$0.6 \%$ & $23.7 \%$ & $9.7 \%$ & $3.0 \%$ & $7.2 \%$ & $65.1 \%$ & $3.2 \%$ & - & $14.9 \%$ & $44.9 \%$ & 3.31 \\
$0.3 \%$ & $6.3 \%$ & $6.0 \%$ & $1.0 \%$ & $5.4 \%$ & $32.3 \%$ & $1.8 \%$ & $5.2 \%$ & - & $18.2 \%$ & 3.48 \\
$0.1 \%$ & $6.6 \%$ & $4.5 \%$ & $0.6 \%$ & $1.6 \%$ & $73.8 \%$ & $0.7 \%$ & $4.1 \%$ & $7.3 \%$ & - & 4.78 \\
\hline
\end{tabular}

Note: Each column $i$ shows the default probabilities of the other banks, conditional on the default of bank $i$. The last column shows the distance to default for all banks.

for instance, the default of bank 6 hits bank 10 harder than bank 5 , although bank 10 has a larger distance to default than bank 5. So, the distance to default, which is based on the marginal distribution of the asset value only, is a reasonable but not perfect indicator of whether the bankruptcy of a bank will have a small or large impact on the system.

To demonstrate the difference between systematic and idiosyncratic shocks, we assume that a fraction $(1-a)$ of the distance to default $d d_{i}$ hits bank $i$ as an idiosyncratic shock $z_{i}^{i d i o}=-(1-a) d d_{i}$. We then draw a systematic shock $z_{i}^{s}$ such that this bank is in default, i.e., $z_{i}^{s}+z_{i}^{i d i o} \leq-d d_{i}$. Given this systematic shock, we simulate the conditional distribution of all banks' asset values using the technique described in appendix 2. Hence, the simulation for the other banks is conditioned on the systematic shock only. This simulation is done for various levels of $a$ ranging from 0 to 1 . We run 100,000 simulations where $z_{i}^{s}+z_{i}^{i d i o} \leq-d d_{i}$ for each defaulting bank and each level $a$.

Note that we compute the conditional distribution of $V$ using the estimated covariance matrix $\hat{\Sigma}$. As an alternative, one could assume a factor model, which would also allow a decomposition into 
Table 6. For Each Bank $i$, Expected Shortfall for All Other Banks Conditional on the Default of Bank $i$

\begin{tabular}{|c|r|r|r|r|r|r|r|r|r|r|}
\hline \multicolumn{10}{|c|}{ Bank } \\
\hline $\boldsymbol{a}$ & $\mathbf{1}$ & \multicolumn{1}{|c|}{$\mathbf{2}$} & $\mathbf{3}$ & \multicolumn{1}{c|}{$\mathbf{4}$} & \multicolumn{1}{c|}{$\mathbf{1}$} & \multicolumn{1}{c|}{$\mathbf{1}$} & $\mathbf{7}$ & \multicolumn{1}{c|}{} & \multicolumn{1}{c|}{$\mathbf{9}$} & \multicolumn{1}{c|}{} \\
\hline 0 & 77 & 168 & 192 & 139 & 267 & 170 & 235 & 144 & 165 & 180 \\
0.1 & 85 & 223 & 241 & 169 & 305 & 267 & 256 & 188 & 218 & 262 \\
0.25 & 103 & 385 & 370 & 241 & 404 & 643 & 315 & 306 & 366 & 558 \\
0.5 & 157 & 1170 & 897 & 492 & 769 & 3059 & 528 & 835 & 1133 & 2541 \\
0.75 & 263 & 3835 & 2424 & 1118 & 1669 & 12568 & 1011 & 2611 & 4227 & 11615 \\
0.9 & 370 & 7566 & 4411 & 1882 & 2721 & 25791 & 1547 & 5201 & 9111 & 24845 \\
1 & 469 & 11550 & 6498 & 2676 & 3782 & 38814 & 2069 & 8071 & 14460 & 37513 \\
\hline
\end{tabular}

Note: The shortfall (in $£ \mathrm{~m}$ ) is computed for different ratios of idiosyncratic to systematic shocks (first column). The shock that causes bank $i$ 's default is assumed to consist of a systematic part $(a)$ and an idiosyncratic part $(1-a)$.

systematic and idiosyncratic shocks. Such a model, however, would just be equivalent to imposing a special structure on $\hat{\Sigma}$. If the aim is to get a quick impression of the difference in magnitude of expected shortfall that comes with the stress assumption, our suggested decomposition is perhaps the simplest and most direct way. As a measure of systemic importance of bank $i$, we compute the expected shortfall for all other banks conditional on the default of bank $i$. That is

$$
E S_{i}=\frac{1}{S} \sum_{s=1}^{S} \sum_{k=1, k \neq i}^{N} \max \left(D_{k}(T)-V_{k}^{s}(T), 0\right),
$$

where $N$ is the number of banks and $S$ is the number of simulation runs. If all deposits are insured, the expected shortfall is equal to the liability of the deposit insurer. Therefore, we can interpret $E S_{i}$ as the increase in the liability of the deposit insurer that results from the failure of bank $i$.

In line with our intuition, we find that systematic shocks constitute a much bigger threat for financial stability than idiosyncratic shocks. Table 6 shows expected shortfall (in £m) conditional on each 
Figure 2. Systematic versus Idiosyncratic Shocks

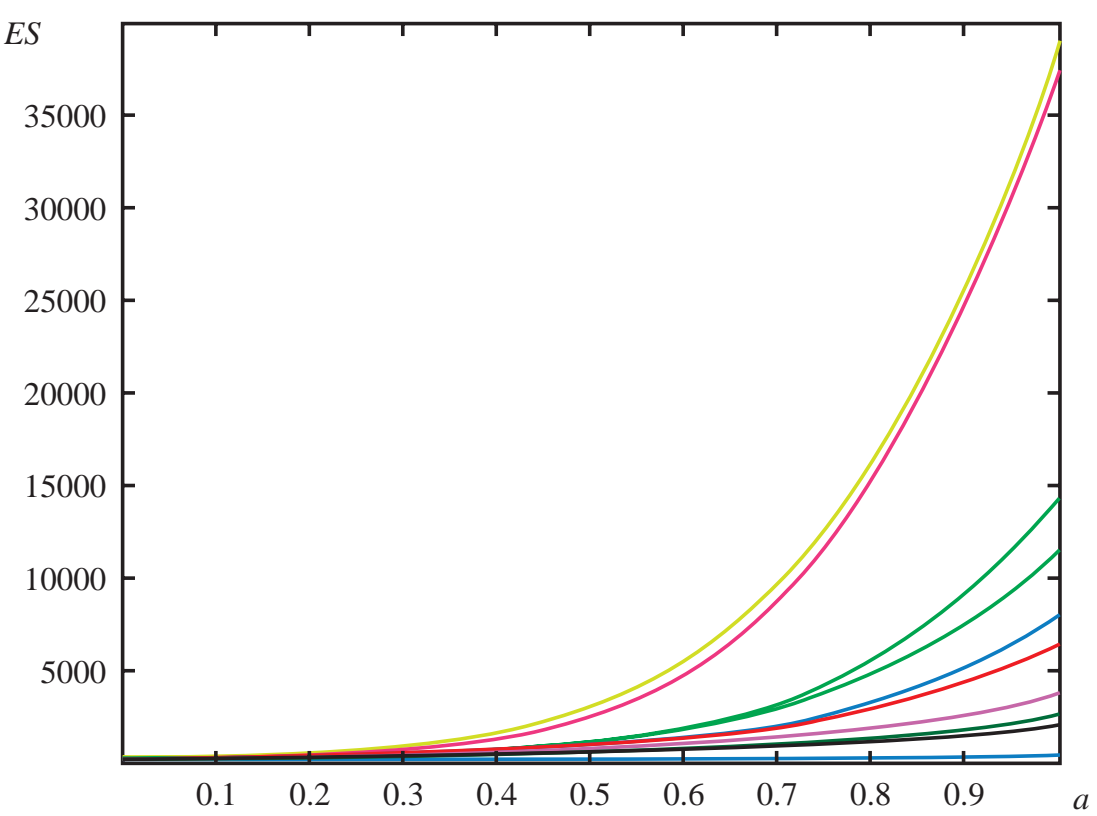

Note: For each bank $i$ of the ten banks, the expected shortfall ES for all other banks conditional on the default of bank $i$ is plotted for different weights of the systematic component $a$ of the shocks. The shock that causes bank $i$ 's default is assumed to consist of a systematic part $(a)$ and an idiosyncratic part $(1-a)$.

bank's default for different levels of $a$. A completely idiosyncratic shock is simulated whenever $a=0$ and the shock is assumed to be completely systematic in the case of $a=1$. Figure 2 illustrates the results.

From the results, we can see that when defining a stress-testing framework for a financial stability assessment, we have to be precise about which situation we want to analyze. Idiosyncratic shocks because of fraud will have a much smaller impact on the banking system than a systemwide shock of similar magnitude. Our approach allows us to come up with measures of systemic importance that combine both aspects of systemic risk, the correlation between banks' assets 
Table 7. Number of Simultaneously Defaulting Banks across Simulations Based on Different Estimates of the Matrix $L$

\begin{tabular}{|c|r|r|r|}
\hline Defaults & Entrop & A & B \\
\hline 0 & 95335 & 95335 & 95335 \\
1 & 3985 & 4005 & 3941 \\
2 & 443 & 448 & 473 \\
3 & 137 & 123 & 144 \\
4 & 62 & 51 & 55 \\
5 & 24 & 26 & 19 \\
6 & 10 & 8 & 14 \\
7 & 3 & 3 & 9 \\
8 & 0 & 0 & 7 \\
9 & 1 & 1 & 3 \\
10 & 0 & 0 & 0 \\
\hline $\begin{array}{l}\text { Note: The results in the column labeled "Entrop" are based } \\
\text { on the solution of the relative entropy minimization. The } \\
\text { matrix } A \text { ( } B \text { ) is an estimate of } L \text { with the highest (lowest) } \\
\text { probability of a single default we were able to find. }\end{array}$ \\
\hline
\end{tabular}

as well as contagion. Regulators can therefore identify banks that are crucial for the stability of the banking sector.

\section{Conclusions}

This paper has outlined a new framework for systemic financial stability analysis for banking systems, which relies mainly on easily observable market data. We apply this framework to the ten major UK banks and suggest a stress-testing procedure. Our motivation stems from the fact that for the analysis of systemic risk-the large-scale breakdown of financial intermediation - the main events of interests are the joint failures of major financial institutions. Therefore it is 
essential to capture two major sources of risk that can lead to simultaneous insolvencies. This requires the consideration of both correlated exposures and credit interlinkages. In most existing studies, attention is focused exclusively on domino effects that result from interlinkages, when single institutions fail ceteris paribus. One of our main results is that the existing approach potentially underestimates joint default events by a significant margin and that considering the two sources of systemic risk indeed matters.

For stress testing we demonstrate how the assumption of a default of a major institution can be simulated consistently with the risks inherent in the bank's assets. We do so by considering the conditional covariance structure of bank asset returns that result from the failure of one institution and study how this changed covariance structure influences domino effects of defaults. Thus we carry previous stress tests for interlinkages a significant step further by embedding these stress tests in a coherent risk analysis. Furthermore, we analyze the role of the assumption of idiosyncratic defaults in the stress testing of interlinkages that was frequently used in the previous literature. We demonstrate that this assumption leads to a much lower impact on the rest of the banking system than assuming that the source of the shock is systematic. Stress tests of interlinkages therefore underestimate the impact of bank breakdowns on the stability of the financial system. The empirical analysis uncovers substantial differences between individual banks concerning their impact on others in stress scenarios and clearly identifies institutions with a high systemic impact.

We hope that our results will be useful in the search for a canonical model to perform risk assessment for banking systems for institutions in charge of systemic financial stability. Since our method relies mainly on market data, it can be more easily applied than methods relying strongly on proprietary information such as loan registers and supervisory data. While such data sources are very rich and allow a more detailed analysis of risk factors, their drawback is that they are not widely available and usually under the close control of national supervisory bodies. Provided the system under consideration is financially highly developed - such as, for instance, in the United Kingdom - our method shows a workable alternative to naive single-institution analysis for systemic risk monitoring. We therefore believe that the approach outlined here is interesting for 
supranational institutions like the International Monetary Fund or the European Central Bank who do not have access to proprietary supervisory data sources but who are interested in financial stability assessment. The parsimony in data has the advantage that our approach is more easily replicable than proprietary data models and might thus be a useful building block to enhance our understanding of systemic risk monitoring for financial stability analysis through studies of other banking systems.

\section{Appendix 1. The Marginal Approach}

To simulate joint defaults neglecting the correlation structure, we use the following procedure. The marginal distribution of $V_{i}(T)$ is given by

$$
V_{i}(T)=V_{i}(0) * \exp \left(\left[\mu_{i}-\frac{1}{2} \sigma_{i}^{2}\right] T+\sigma_{i} B_{i}(T)\right),
$$

where $B_{i}(T) \sim N(0, T)$. To generate a scenario $s$ we randomly draw an $N \times 1$ vector $\tilde{B}^{s}$ of independent standard normal random variables and calculate

$$
V_{i}^{s}(T)=V_{i}(0) * \exp \left(\left[\hat{\mu}_{i}-\frac{1}{2} \hat{\sigma}_{i}^{2}\right] T+\hat{\sigma}_{i} \sqrt{T} \tilde{B}_{i}^{s}\right),
$$

where $\hat{\mu}_{i}$ and $\hat{\sigma}_{i}$ are the estimates of $\mu_{i}$ and $\sigma_{i}$. Then we count the number of banks for which their asset values $V_{i}^{S}(T)$ is less than their total liabilities $D_{i}(T)$.

\section{Appendix 2. Conditional Default}

In section 7 we assume that the regulator learns that bank $i$ is in default. We ask the question, what can be deduced about the stability of the system given this information, i.e., what is the conditional distribution of the asset values of all other banks given the default of bank $i$ ? To do the simulations, we first reorder the banks such that the defaulting bank is the first one. Then we simulate asset returns according to the procedure below and count the number of conditionally defaulting banks. 
The (asset) return of bank $i$ is defined as $R_{i}(T)=$ $\ln \left(V_{i}(T) / V_{i}(0)\right)$. We denote the vector of joint returns by $R(T)=$ $\left(R_{1}(T), \ldots, R_{N}(T)\right)^{\prime} . R(T)$ is a multivariate normal random variable with $E\left[R_{i}(T)\right]=T\left(\mu_{i}-\frac{1}{2} \sigma_{i}^{2}\right)=T \alpha_{i}$ and $\operatorname{Var}[R(T)]=T \Sigma$, i.e., $R(T) \sim M V N(\alpha, T \Sigma)$, where $\alpha=\left(\alpha_{1}, \ldots, \alpha_{N}\right)^{\prime}$. Consider the following partition

$$
R(T)=\left[\begin{array}{c}
R^{1}(T) \\
R^{2}(T)
\end{array}\right] \quad \alpha=\left[\begin{array}{c}
\alpha^{1} \\
\alpha^{2}
\end{array}\right] \quad \Sigma=\left[\begin{array}{ll}
\Sigma^{11} & \Sigma^{12} \\
\Sigma^{21} & \Sigma^{22}
\end{array}\right],
$$

where the $N$ random variables are partitioned into $n_{1}$ and $n_{2}$ variates $\left(n_{1}+n_{2}\right)=N \cdot R^{2}(T)$ given $R^{1}(T)$ is multivariate normally distributed with $E\left[R^{2}(T) \mid R^{1}(T)\right]=T \alpha^{2}+\Sigma^{21}\left(\Sigma^{11}\right)^{-1}\left(R^{1}-T \alpha^{1}\right)$ and $\operatorname{Var}\left[R^{2}(T) \mid R^{1}(T)\right]=T\left(\Sigma^{22}-\Sigma^{21}\left(\Sigma^{11}\right)^{-1} \Sigma^{12}\right) .{ }^{19}$

For our simulation, we factor $\Sigma$ using the Cholesky decomposition such that $\Sigma=U^{\prime} U$. Now define the random variable $S=T \alpha+$ $\sqrt{T} U^{\prime} Z$ where $Z \sim M V N\left(0_{N, 1}, I_{N, N}\right)$. Evidently, $S$ has the same distribution as $R$, i.e., $S \sim M V N(T \alpha, T \Sigma)$. Partitioning $S, U, Z$ conformably to $R$ gives

$$
S=\left[\begin{array}{l}
S^{1} \\
S^{2}
\end{array}\right] \quad Z=\left[\begin{array}{l}
Z^{1} \\
Z^{2}
\end{array}\right] \quad U=\left[\begin{array}{cc}
U^{11} & U^{12} \\
0 & U^{22}
\end{array}\right] .
$$

This means that

$$
S^{1}=T \alpha^{1}+\sqrt{T}\left(U^{11}\right)^{\prime} Z^{1}
$$

and

$$
S^{2}=T \alpha^{2}+\sqrt{T}\left(U^{12}\right)^{\prime} Z^{1}+\sqrt{T}\left(U^{22}\right)^{\prime} Z^{2} .
$$

To simulate the conditional distribution of $S^{2}$ given $S^{1}=R^{1}(T)$, we first calculate $Z^{1}$ as

$$
Z^{1}=\frac{1}{\sqrt{T}}\left(\left(U^{11}\right)^{\prime}\right)^{-1}\left(R^{1}(T)-T \alpha^{1}\right) .
$$

Plugging this into the definition of $S^{2}$ yields

$$
S^{2}=T \alpha^{2}+\left(U^{12}\right)^{\prime}\left(\left(U^{11}\right)^{\prime}\right)^{-1}\left(R^{1}(T)-T \alpha^{1}\right)+\sqrt{T}\left(U^{22}\right)^{\prime} Z^{2} .
$$

\footnotetext{
${ }^{19}$ See Ramanathan $(1993,109)$.
} 
We know that $S^{2}$ given $S^{1}$ is multivariate normally distributed. It remains to be shown that $\left.E\left[S^{2} \mid R^{1}(T)\right)\right]=E\left[R^{2}(T) \mid R^{1}(T)\right]$ and $\operatorname{Var}\left[S^{2} \mid R^{1}(T)\right]=\operatorname{Var}\left[R^{2}(T) \mid R^{1}(T)\right]$. Note that $E\left[S^{2} \mid R^{1}(T)\right]=$ $T \alpha^{2}+\left(U^{12}\right)^{\prime}\left(\left(U^{11}\right)^{\prime}\right)^{-1}\left(R^{1}(T)-T \alpha^{1}\right)$ and

$$
\left(U^{12}\right)^{\prime}\left(\left(U^{11}\right)^{\prime}\right)^{-1}=\left(U^{12}\right)^{\prime} U^{11}\left(U^{11}\right)^{-1}\left(\left(U^{11}\right)^{\prime}\right)^{-1} .
$$

Now $\left(U^{12}\right)^{\prime} U^{11}=\Sigma^{21}$ and $\left(U^{11}\right)^{-1}\left(\left(U^{11}\right)^{\prime}\right)^{-1}=\left(\Sigma^{11}\right)^{-1}$. Hence

$$
E\left[S^{2} \mid R^{1}(T)\right]=T \alpha^{2}+\Sigma^{21}\left(\Sigma^{11}\right)^{-1}\left(R^{1}(T)-T \alpha^{1}\right) .
$$

The variance of $S^{2}$ given $S^{1}=R^{1}(T)$ is $T\left(U^{22}\right)^{\prime} U^{22}$. By the definition of $U$ it holds that

$$
\begin{aligned}
\left(U^{22}\right)^{\prime} U^{22} & =\Sigma^{22}-\left(U^{12}\right)^{\prime} U^{12} \\
& =\Sigma^{22}-\left(U^{12}\right)^{\prime} U^{11}\left(U^{11}\right)^{-1}\left(\left(U^{11}\right)^{\prime}\right)^{-1}\left(U^{11}\right)^{\prime} U^{12} \\
& =\Sigma^{22}-\Sigma^{21}\left(\Sigma^{11}\right)^{-1} \Sigma^{12},
\end{aligned}
$$

which is the same as the variance of $R^{2}(T)$ given $R^{1}(T)$. Hence, the conditional distribution of $S^{2}$ given $S^{1}=R^{1}(T)$ is just the same as that of $R^{2}(T)$ given $R^{1}(T)$.

To generate a scenario $s$ we assume that bank 1 defaults $\left(n_{1}=1\right)$. Let $R_{1}^{*}(T)$ be such that $V_{1}(T)=V_{1}(0) \exp \left(R_{1}^{*}(T)\right)=D_{1}(T)$. Now we randomly draw $R_{1}^{s} \leq R_{1}^{*}(T)$. Given this realization of $R_{1}(T)$, we simulate $S^{2}$ and calculate the asset values of the banks, $V_{2}^{s}(T), \ldots, V_{n}^{s}(T)$. Finally, we count the number of (conditionally) defaulting banks in scenario $s$. The results are based on 100,000 simulations. Note that the procedure can easily be extended to the case where several banks are assumed to be in default.

\section{References}

Allen, Franklin, and Douglas Gale. 2000. "Financial Contagion." Journal of Political Economy 108 (1): 1-34.

Angelini, Paolo, G. Maresca, and Daniela Russo. 1996. "Systemic Risk in the Netting System." Journal of Banking and Finance 20 (5): 853-86.

Black, Fischer, and Myron Scholes. 1973. "The Pricing of Options and Corporate Liabilities." Journal of Political Economy 8: $1637-59$. 
Blien, Uwe, and Friedrich Graef. 1997. "Entropy Optimizing Methods for the Estimation of Tables." In Classification, Data Analysis, and Data Highways, ed. Ingo Balderjahn, Rudolf Mather, and Martin Schader. Berlin: Springer Verlag.

Cocco, Joao F., Francisco J. Gomes, and Nuno C. Martins. 2004. "Lending Relationships in the Interbank Market." IFA Working Paper No. 384.

Degryse, Hans, and Gregory Nguyen. 2004. "Interbank Exposures: An Empirical Analysis of Systemic Risk in the Belgian Banking System." Working Paper, National Bank of Belgium.

Duan, Jin-Chuan. 1994. "Maximum Likelihood Estimation Using Price Data of the Derivative Contract." Mathematical Finance 4 (2): $155-67$.

- 2000. "Correction: Maximum Likelihood Estimation Using Price Data of the Derivative Contract." Mathematical Finance 10 (4): 461-62.

Eisenberg, Larry, and Thomas Noe. 2001. "Systemic Risk in Financial Systems." Management Science 47:236-49.

Elsinger, Helmut, Alfred Lehar, and Martin Summer. 2004. "Risk Assessment for Banking Systems." Working Paper, University of Vienna.

—. 2005. "Using Market Information for Banking System Risk Assessment." SSRN Working Paper, http://ssrn.com/ abstract $=787929$.

Fang, Shu-Cherng, Jay R. Rajasekera, and H.-S. Jacob Tsao. 1997. Entropy Optimization and Mathematical Programming. Boston, London, Dordrecht: Kluwer Academic Publishers.

Furfine, Craig. 2003. "Interbank Exposures: Quantifying the Risk of Contagion." Journal of Money, Credit, and Banking 35 (1): $111-28$.

Humphrey, David B. 1986. "Payments Finality and Risk of Settlement Failure." In Technology and the Regulation of Financial Markets: Securities, Futures and Banking, ed. Anthony Saunders and Lawrence J. White. Lexington, MA: Lexington Books.

Lehar, Alfred. 2005. "Measuring Systemic Risk: A Risk Management Approach." Journal of Banking and Finance 29 (10): 2577-2603.

Merton, Robert C. 1973. "A Rational Theory of Option Pricing." Bell Journal of Economics and Management Science 4: 141-83. 
. 1974. "On the Pricing of Corporate Debt: The Risk Structure of Interest Rates." Journal of Finance 29 (2): 449-70.

Mistrulli, P. E. 2005. "Interbank Lending Patterns and Financial Contagion." Mimeo, Banca d'Italia.

Nicolo, Gianni De, and Myron L. Kwast. 2002. "Systemic Risk and Financial Consolidation: Are They Related?" Journal of Banking and Finance 26 (5): 861-80.

Ramanathan, Ramu. 1993. Statistical Methods in Econometrics. San Diego: Academic Press.

Shibut, Lynn. 2002. "Should Bank Liability Structure Influence Deposit Insurance Pricing?" FDIC Working Paper No. 2002-01.

Upper, Christian, and Andreas Worms. 2004. "Estimating Bilateral Exposures in the German Interbank Market: Is There a Danger of Contagion?" European Economic Review 48:827-49.

VanLelyveld, Iman, and Frank Liedorp. 2004. "Interbank Contagion in the Dutch Banking Sector." DNB Working Paper Series.

Wells, Simon. 2004. "Financial Interlinkages in the United Kingdom's Interbank Market and the Risk of Contagion." Working Paper, Bank of England. 